\title{
Acute adult vitamin A toxicity: Report of a case
}

GREGORY G. MARINO, D.O., LCDR, MC, USNR San Diego, California

JOSEPH P. IACOLUCCI, M.D., CAPT., MC, USN Bremerton, Washington

Vitamin A is commonly used as an additive in many food preparations. It is also present in some medications and can be found as a dietary supplement. Vitamin A toxicity is very uncommon, but when it occurs, it can be serious and even fatal.

Manifestations can be seen on the skin, in the gastrointestinal tract, the liver, the skeleton, and central nervous system. Often when present with acute toxicity, it is not readily recognized and can be confused with viral hepatitis or other intoxications. A careful drug history, including that for vitamins and dietary supplements, and a high index of suspicion, can lead to the correct diagnosis. There is no specific treatment for vitamin A intoxication, but prompt cessation of the drug often results in complete resolution.

Patients should be instructed not only about the possible side effects of prescription medications, but it is also important for them to understand that overuse of nonprescription preparations, including nutritional supplements and vitamins, can result in serious toxicity. Increased media coverage has focused public attention on diet and exercise, and nutritional systems and diet plans have become profitable enterprises. These factors may result in increasing numbers of patients with health food and vitamin induced medical problems presenting to the primary care practitioner.

The various vitamins have many therapeutic uses. For example, vitamin A, or a derivative, is used to treat severe acne and other dermatologic disorders. Vitamin A preparations occasionally are used to treat some forms of keratitis. The vitamin also has been reported to be effective in improving night vision in patients with visual problems that are secondary to primary biliary cirrhosis ${ }^{1}$ and at reversing postburn immunosuppression in animal models. ${ }^{2}$ Several authors have suggested a possible role for vitamin $\mathrm{A}$ in the prevention of various cancers. $^{3}$
Vitamin A toxicity has been well documented in the medical literature. However, although nearly 600 cases of vitamin A toxicity have been reported, less than 100 cases involved adults. Our report of adult vitamin A toxicity illustrates how significant morbidity can result from ingestion of relatively small amounts of vitamin A over a short period of time.

\section{Report of case}

A 29-year-old white woman, a computer specialist, was admitted complaining of joint pains, nausea, vomiting, and headache. She had been well until 10 days prior to admission, when she had developed pain in her feet and ankles while running. Aspirin and rest failed to alleviate her symptoms, and, 4 days prior to admission, pain developed in her knees, elbows, and wrists. The following day she had begun experiencing nausea, vomiting, and mild, diffuse abdominal discomfort. On the day of admission, she was not able to eat, drink, or walk.

The patient had a history of Raynaud's phenomenon of 4 years' duration, which was being managed successfully with nifedipine. At age 23 she had undergone tonsillectomy. She did not smoke and rarely drank alcohol. Her family history was not remarkable. Her medications on admission included the nifedipine, oral contraceptives, and a daily multiple vitamin. Also, 2 years prior to admission, she had begun taking 10,000 units of vitamin A a day to prevent acne, and she had increased the amount to 75,000 units per day 6 months prior to admission.

On physical examination, the patient appeared acutely ill. She was afebrile, with a pulse rate of 60 beats/minute, respiratory rate of 20 /minute, and blood pressure of $124 / 70 \mathrm{~mm}$. $\mathrm{Hg}$. The head and neck examination was remarkable for crusted skin lesions about the lips, with an otherwise normal mouth and pharynx. The neck was supple, without thyromegaly or adenopathy, and the ears were normal. The optic fundi were normal, with sharp optic discs. The breasts were normal, and the chest wall was clear to auscultation. The heart had a regular rate and rhythm; a grade I/VI systolic ejection murmur was noted at the second left intercostal space. The abdominal examination showed mild right-upper-quadrant tenderness and a liver that percussed to $10 \mathrm{~cm}$. No masses were palpated. Rectal and pelvic examinations revealed no abnormalities. There was no axillary or inguinal adenopathy. The skin showed desquamation about the palms and elbows. There was pain on movement of the left ankle, but no joint erythema or effusions were present. The neurologic examination revealed no abnormalities. 
The complete blood count revealed the following values: hemoglobin concentration, $12.5 \mathrm{gm} . / \mathrm{dl}$.; hematocrit reading, 36.7 percent; leukocyte count, $9,100 / \mathrm{cu}$. $\mathrm{mm}$; ; and platelet count, 188,000/cu. mm. Laboratory serum values were as follows: sodium, $138 \mathrm{mEq} . / \mathrm{L}$; serum potassium, $4.3 \mathrm{mEq} . / \mathrm{L}$; ; serum chloride, $100 \mathrm{mEq}$./ L.; serum bicarbonate, $31 \mathrm{mEq} . / \mathrm{L}$.; serum creatinine, 1.0 $\mathrm{mg} . / \mathrm{dl}$.; and serum amylase, 69 Somogyi units/dl. The blood urea nitrogen level was $14 \mathrm{mg} . / \mathrm{dl}$. The serum calcium, phosphorus, and total albumin values were 15.3 $\mathrm{mEq} . / \mathrm{L} ., 3.0 \mathrm{mEq} . / \mathrm{L}$., and $3.9 \mathrm{gm} . / \mathrm{dl}$., respectively. The serum lactic dehydrogenase level was 587 I.U. (normal, 0-200 I.U.), the serum glutamic-oxaloacetic transaminase value was 111 I.U. (normal, 0-42 I.U.), and the serum glutamic-pyruvic transaminase level was 84 I.U. (normal, 0-45 I.U.). The prothrombin time was 19 seconds, with a control of 12 seconds at 36 percent activity. It corrected to 100 percent activity with a 1:1 dilution. The partial thromboplastin time was 40 seconds, with a control of 34 seconds. Serologic testing for hepatitis A and hepatitis B was negative. Antinuclear antibody and rheumatoid factor tests were negative, as was a Monospot test. The serum thyroid-stimulating hormone value was $1.0 \mathrm{mU} . / \mathrm{ml}$., the serum thyroxine iodine value $4.5 \mathrm{mcg}$./ dl., and the parathyroid hormone was $64 \mathrm{pg} . / \mathrm{ml}$. The vitamin A level was $132 \mathrm{mcg} . / \mathrm{dl}$. (normal, $20-80 \mathrm{mcg} . / \mathrm{dl}$.); repeat testing returned a value of $158 \mathrm{mcg}$./dl. The vitamin D level was normal. A chest $\mathrm{x}$-ray and radiographs of the hands and feet were unremarkable.

On the fifth hospital day, vitamin A toxicity was diagnosed. The patient's hypercalcemia was managed with saline diuresis, and, at discharge 15 days later, the serum calcium value was $10.4 \mathrm{mEq} . / \mathrm{L}$. Her bone symptoms resolved with the normalization of the serum calcium level. She was given vitamin $\mathrm{K}$ (10 mg. per day intravenously) for 3 days. She had no hemorrhagic episodes, and at discharge the prothrombin time was 14 seconds, with a control of 12 seconds.

On discharge the liver function tests were still abnormal, but eight weeks following discharge, the prothrombin time and the liver function values were normal. However, the patient returned complaining of malaise 12 weeks following discharge. Physical examination revealed cheilosis, patchy alopecia, and desquamation of the skin of the palms of the hands. The patient denied taking vitamins or food supplements, but her vitamin A level proved to be $167 \mathrm{mcq}$./dl. Confronted with this laboratory value, she subsequently admitted to resumption of her vitamin intake. She was referred for psychiatric evaluation.

\section{Discussion}

This case illustrates the potentially serious complications of ingesting the fat-soluble vitamin A in amounts in excess of the recommended daily allowance, which is 2,000 I.U. for infants, 2,500 I.U. for children, and 5,000 I.U. for adults. ${ }^{4}$

Most cases of hypervitaminosis A are completely reversible with cessation of ingestion of the vitamin. However, hepatic cirrhosis can occur with
TABLE 1. SIGNS AND SYMPTOMS OF VITAMIN A TOXICITY IN ADULTS.

Skin changes (desquamation of the palms and soles; cheilosis; coarsening; alopecia; localized hyperpigmentation)

Headache

Bone and joint pain

Fever

Nausea

Depression

Schizophrenia

Hepatic dysfunction (icterus, hepatic encephalopathy, hepatomegaly)

Coagulopathy

Neuritis

Soft-tissue, tendon, and ligament calcification

prolonged intake, and fatalities from hepatic necrosis and subsequent liver failure have been reported. ${ }^{5}$ Chronic ingestion can also result in calcification of tendons, ligaments, and soft tissues, as well as hypercalcemia. Pseudotumor cerebri and chronic headache syndromes are common manifestations of hypervitaminosis A. ${ }^{6-9}$ Less commonly, psychiatric symptoms of severe depression or schizophrenia have been reported with prolonged vitamin $\mathrm{A}$ intake. ${ }^{10} \mathrm{~A}$ complete list of the signs and symptoms of adult vitamin A toxicity is presented in Table 1. Hypervitaminosis A also is potentially teratogenic.

Following ingestion, vitamin $\mathrm{A}$ is absorbed and esterified with long-chain fatty acids and transported to the liver in chylomicrons. In the liver, the retinyl esters are stored in hepatocytes and Ito cells, which are specialized hepatic sinusoidal cells. Normally, vitamin A is transported in plasma as a free alcohol, retinol, bound to a specific carrier termed retinol-binding protein $(\mathrm{RBP}){ }^{11} \mathrm{RBP}$, which is produced in the liver, also regulates vitamin A release from the hepatocyte. It is thought that by binding retinol, RBP protects normal tissues from free vitamin $A$. At the target cell, vitamin $A$ is transferred from RBP by a series of cellular-binding proteins in relay fashion, thus delivering the vitamin to the nucleus, where it serves in the induction of the synthesis of specific proteins. ${ }^{12}$ Toxicity results when the capacity of RBP is exceeded and free retinol is circulated.

The amount of vitamin/duration of intake required to produce toxicity is not known. Ingestion of large amounts of vitamin A (in excess of 500,000 I.U.) can produce acute toxicity. Various authors $\mathrm{s}^{6,13}$ have reported toxicity following several months to years of ingestion levels of 50,000 I.U. per day. Hatoff and associates ${ }^{7}$ reported a case of a 42 -yearold man who had ingested 25,000 I.U. for 10 years 
prior to the onset of symptoms subsequent to acute viral hepatitis. These authors hypothesized that in these patients the binding capacity of RBP had been approached but not exceeded prior to the viral insult. Acute liver toxicity then resulted in transient depression of hepatic protein synthesis, including RBP, and disruption of hepatocytes and Ito cells led to the release of amounts of stored vitamin A that exceeded the binding capacity of the available RBP.

The exact mechanism whereby excessive vitamin A causes tissue damage remains unknown. In soft tissues, the vitamin is thought to stimulate collagen formation, and in bone, it seems to act through stimulation of osteoclast activity. ${ }^{9}$

\section{Summary}

Fatalities from vitamin A intoxication are rare, but have been reported. There is no specific therapy for it, but prompt cessation of the agent often leads to complete recovery. A careful drug and dietary history can lead to the correct diagnosis of vitamin A toxicity in a patient who presents with a multisystem illness of uncertain etiology.

1. Walt, R.P., et al.: Vitamin A treatment for night blindness in primary biliary cirrhosis. Br Med J 288:1030-1, 7 Apr 84

2. Fusi, S., et al.: Reversal of postburn immunosuppression by administration of vitamin A. Surgery 96:330-5, Aug 84

3. Kummet, T., et al.: Vitamin A. Evidence for its preventive role in human cancer. Nutr Cancer 5:96-106, 1983

4. Food and Nutrition Board, National Research Council: Recommended dietary allowances. Ed. 8. National Academy of Science, Washington, D.C., 1974

5. Bush, M.E., and Dahms, B.B.: Fatal hypervitaminosis A in a neonate, Arch Pathol Lab Med 108:838-42, Oct 84

6. Farris, W., and Erdman, J.W., Jr.: Protracted hypervitaminosis A following long-term, low-level intake. JAMA 247:1317-8, 5 Mar 82
7. Hatoff, D.E., et al.: Hypervitaminosis A unmasked by acute viral hepatitis. Gastroenterology $82: 124-8$, Jan 82

8. Baxi, S.C., and Dailey, G.E., III.: Hypervitaminosis A. A cause of hypercalcemia. West J Med 137:429-31, Nov 82

9. Frame, B., et al.: Hypercalcemia and skeletal effects in chronic hypervitaminosis A. Ann Int Med 80:44-8, Jan 74

10. Braunwald, E., et al., eds.: Harrison's Principles of internal medicine. Ed. 11. McGraw-Hill Book Co., New York, pp. 464-5, 1987

11. Kanai, M., Raz, A., and Goodman, D.S.: Retinol-binding protein. The transport protein for vitamin A in human plasma. J Clin Invest 47:2025-44, Sep 68

12. The pathophysiological basis of vitamin A toxicity. Nutr Rev 9:272-4, Sep 82

13. Smith, F., and Goodman, D.S.: Vitamin A transport in human vitamin A toxicity. N Engl J Med 294:805-8, 8 Apr 76

Guarascio, P., et al.: Liver damage with reversible portal hypertension from vitamin A intoxication. Demonstration of Ito cells. J Clin Pathol 36:769-71, Jul 83

Herbert, V.: Toxicity of $25,000 \mathrm{IU}$ vitamin A supplements in "health" food users. Am J Clin Nutr 36:185-6, Jul 82

James, M.B., et al.: Hypervitaminosis A. A case report. Pediatrics 69:112-5, Jan 82

Lippe, B., et al.: Chronic vitamin A intoxication. A multisystem disease that could reach epidemic proportions. Am J Dis Child 135:634-6, Jul 81 Podell, R.N.: Vitamin A supplementation. Subclinical overdose "unmasked" by hepatitis. Postgrad Med 74:297-301, Sep 83

Weber, F.L., et al.: Reversible hepatotoxicity associated with hepatic vitamin A accumulation in a protein-deficient patient. Gastroenterology 82:118-23, Jan 82

The opinions or assertions expressed herein are those of the authors and are not to be construed as being official or as reflecting the views of the Department of the Navy or the naval service at large.

Dr. Marino is a fellow, Department of Internal Medicine, Division of Hematology/Oncology, Naval Hospital, San Diego, California. When the paper was written, Dr. Iacolucci was on the attending staff of the Department of Internal Medicine at the Naval Hospital in San Diego. He is now chief, Department of Internal Medicine, Naval Hospital, Bremerton, Washington.

Dr. Marino, Division of Hematology/Oncology, Naval Hospital, San Diego, California 92134 